\title{
Studying snow cover in European Russia with the use of remote sensing methods
}

\author{
A. A. TELEGINA \\ Department of Land Hydrology, Lomonosov Moscow State University, GSP-1, Leninskie Gory, Moscow 119991, Russia \\ annatelegina29@gmail.ru
}

\begin{abstract}
Satellite data are used to study water balance in large river basins in the East European Plain. For this purpose, the accuracy of estimates of snow water equivalent (SWE) based on microwave remote sensing data was evaluated through the comparison of these data with SWE measurements in open and forested areas. The errors of the SWE estimates, evaluated as their relative root-mean-square deviations from the measured values, are maximal in the Northern Dvina basin (53\%); for the Oka and Don river basins, the errors are 35 and $33 \%$, respectively. The main problems of remote sensing for northern river basins occur due to the thick canopy and the high snowpack, whose height exceeds the penetration depth. For the southern regions and midland river basins, a priority problem is due to the presence of liquid water in the snowpack during thaws.
\end{abstract}

Key words snow water equivalent; remote sensing; passive microwave survey; uncertainty; European Russia

\section{INTRODUCTION}

Seasonal snow cover is one of the most widespread and dynamic natural objects and a powerful climate-forming factor. In addition, snow is the most important hydrological resource because in many areas it determines river runoff. Thus, seasonal snow melting determines the spring flood, which, for a considerable part of Russia, is the most specific feature of the water regime. The basic characteristic of snow weight, which allows one to better estimate the expected spring runoff volume is snow water equivalent (SWE), i.e. the depth of water resulting from snow melting.

With the technological developments in the sphere of Earth surface and land cover observations in recent decades, the use of remote sensing to determine snow characteristics is under intensive investigation. The major four electromagnetic spectral bands that are useful for remote sensing of snow are gamma rays, visible and near-infrared, thermal infrared, and microwaves. In this work, the application of the most advanced method of passive-microwave remote sensing is studied. Microwave radiometry, the measurement of the intensity of radiation on frequencies from 6 to $37 \mathrm{GHz}$, has main three advantages:

- universality, in the sense that the measurements of outgoing microwave radiation can be used for remote indication of various parameters, such as atmosphere, land surface, topsoil and snow cover (depending on the choice of frequency sensing);

- all-weather capability, i.e. the relative transparency of the atmosphere for microwave range that makes these data extremely useful for determining snow parameters, especially in sparsely populated territories, where other sources of such data are not available;

- the high spatial and temporal resolution of observations.

However, this method has some disadvantages standing in the way of effective mapping of snow water equivalent from space, such as the poor resolution of $25 \mathrm{~km} \times 25 \mathrm{~km}$, the temporal and spatial evolution of grain size and density, the obscuration by forests, and the presence of liquid water in the snowpack, which means that the point under consideration looks like snow-free land. Also, the propagation of microwave radiation is influenced by the so-called "saturation effect", i.e. changes in the brightness temperature become impossible after some critical snow depth is attained for the given grain size; this critical snow depth is called the "penetration depth" (Tedesco et al, 2010).

The microwave radiation emitted from the soil and scattered by snow grains decreases with increasing snow depth. Because higher frequencies are more sensitive to the grain size, the brightness temperature at these frequencies (e.g. $37 \mathrm{GHz}$ ) decreases more than that at lower frequencies (e.g. $18 \mathrm{GHz}$ ), so the difference between them will increase with snow depth until a saturation point is reached. 
Based on this concept, several SWE estimation algorithms have been developed for passive microwave observations. The algorithm commonly used is that of Chang et al. (1987), which estimates SWE as the 18- and 37-GHz brightness temperature difference, multiplied by a constant. The $37-\mathrm{GHz}$ data are sensitive to snow pack scattering while the 18-GHz data are less affected by snow. Foster et al. (2005) have modified this algorithm using spatially and temporally varying constants, which account for forest cover fraction and snow crystal size variations by:

$$
S W E-F_{c}\left(T_{18}-T_{37}\right)
$$

where $F$ is the fractional forest cover factor and $c$ is parameterized according to the Sturm snow class categories (Sturm et al., 1995) and the time of year. $T_{18}$ and $T_{37}$ are the horizontally polarized brightness temperatures at $18 \mathrm{GHz}$ and $37 \mathrm{GHz}$, respectively (Donga et al., 2005).

Retrieval SWE data are available open access and cover the whole world; however, the use of the same algorithm for different physiographic conditions results in the need to check data representativeness for each investigated territory. The aim of the study is spatial-temporal analysis of the available microwave data of passive remote sensing and estimation of the possibility of using passive microwave remote sensing for studying snow cover in European Russia. To achieve the main objective, the following tasks were completed: the comparison and objective assessment of the main methods of SWE retrieval; the estimation of the accuracy of the obtained information by the comparison of those data with the actual ground-based SWE data from meteorological stations for a long period; the assessment of the impact of variations of the basic meteorological elements on data accuracy; also the major factors influencing the uncertainty in European Russia are revealed and estimated. The estimation was carried out for the period from 2002 until 2010 with the use of remote sensing SWE data from the National Snow and Ice Data Center through their comparison with ground-based data from meteorological stations.

\section{DATA}

\section{Passive microwave observations}

A complete time series of radiometer data from 1978 to 2010 was acquired from the National Snow and Ice Data Center (NSIDC) in Boulder, Colorado, USA. For the years 1978-1987, the Scanning Multichannel Microwave Radiometer (SMMR; Knowles et al., 2002) data from Nimbus 7 were used, whereas for 1987-2010, Special Sensor Microwave/Imager (SSM/I; Armstrong et al., 1994) data from the Defense Meteorological Satellite Program (DMSP) D-11 and D-13 were used. For the years 2002-2010, data from the Advanced Microwave Scanning Radiometer (AMSR-E; Knowles et al., 2006) on board the Aqua satellite were acquired. The space-borne brightness temperature measurements are in the EASE-Grid north azimuthal equalarea projection with a nominal resolution of $25 \mathrm{~km} \times 25 \mathrm{~km}$ (Armstrong et al., 1994).

As noted above, the considered research used only data for the years 2002-2010 from the Advanced Microwave Scanning Radiometer (AMSR-E) of NASA's Earth Observing System (EOS) Aqua satellite. Since 2002, NASA has been issuing daily maps of SWE for the entire globe with 0.2 grid pixel size of the latitude-longitude projection.

\section{In situ snow observations}

Meteorological data were collected from ground-based weather stations within the study area. The data included daily observations of air temperature, air humidity and precipitation amount. Moreover, at the same stations, daily values of snow depth were recorded. In addition, SWE data received from in situ snow surveys were used for analyses each 5th day (for winter and spring 2010) and each 10th day (for period 2002-2010).

After general and primary comparison of the ground-based data from the meteorological stations with corresponding pixels of the remote sensing data raster, it was decided to average the data within the boundaries of river watersheds, which is more suitable for hydrological purposes. All measurements were averaged within the boundaries of nine river watersheds with different size and geographical location: Mezen, Pechora, Onega, Northern Dvina, Moskva, Oka, Kama, Volga, and Don. 


\section{Error assessment}

The error of the SWE estimate, evaluated as its relative root-mean-square deviation from the measured values, is maximal in the Northern Dvina watershed, where its average value reaches $53 \%$; for the Oka and Don river basins, the errors were 35 and 33\%, respectively. A tendency in the seasonal variations of the estimated and in situ SWE can be clearly seen in Fig. 1; the difference between the remote sensing measurements and ground-based data decreases from the north to the south and from the Pechora to the Don, respectively.
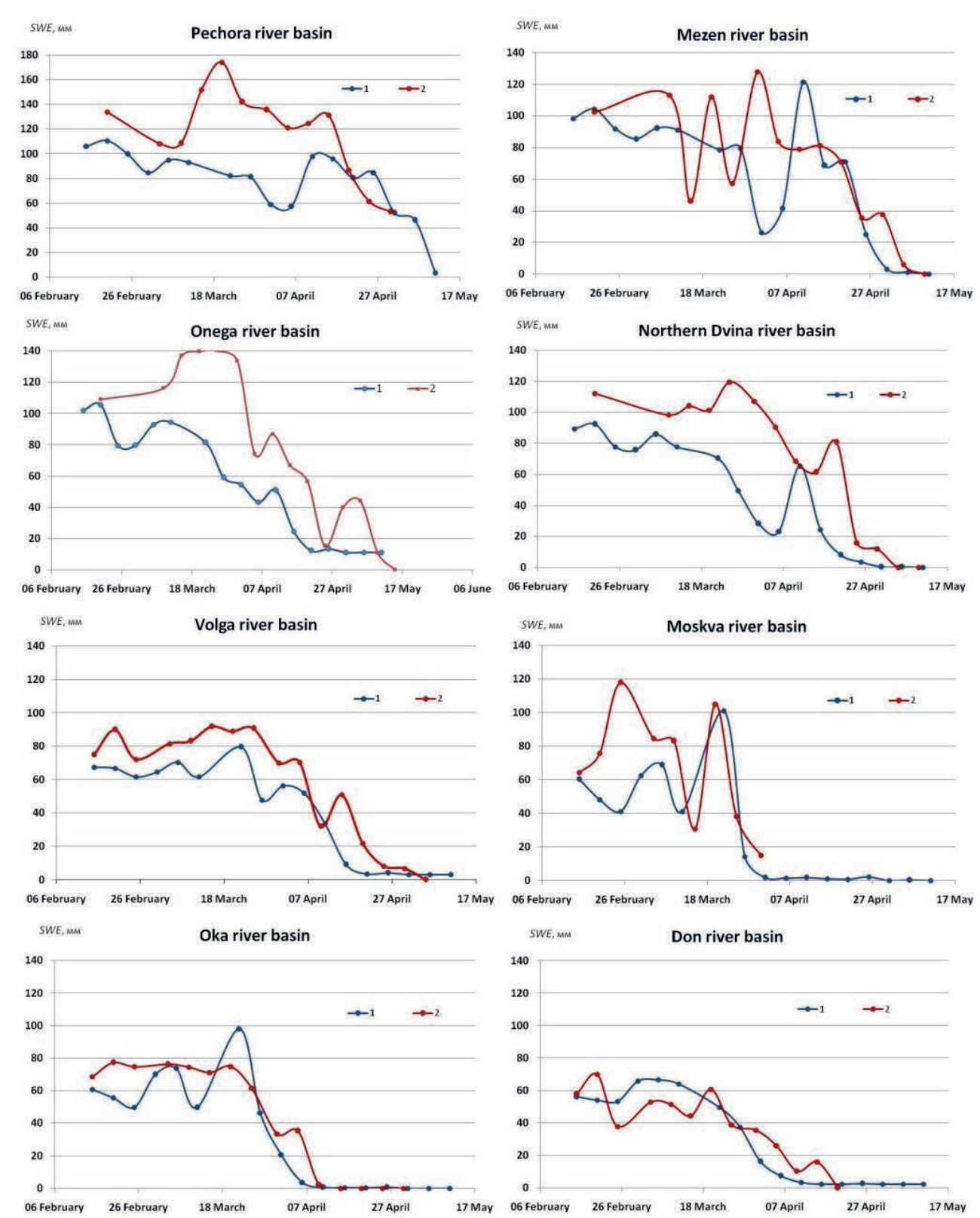

Fig. 1 Comparison of estimated (1) and in situ (2) SWE data values for spring snowmelt period of 2010.

Variations of the average deviation allow three distinctive zones to be identified: the northern European Russia with the greatest errors, the midland, and the southern part with the lowest errors. Based on this estimation, the main factors that lead to errors and their distributions for different watersheds along East European Plain can be found. 


\section{CONFUSING FACTORS}

Therefore, the main problems of remote sensing for northern river basins of the European Plain are the thick canopy cover and the high snowpack, whose height exceeds the penetration depth. For the southern regions and midland river basins, priority problems are the frequent disagreement between fluctuations of the temporal distribution of precipitation and the estimated values of SWE; another problem is the inverse relation between the estimated SWE and air temperature. That is why it is very important to take thaws into account.

Figure 2 gives an example of comparison of a temporal distribution of measured and estimated SWE with meteorological data on precipitation and average air temperature for the basin of the Don. The plot clearly shows the influence of thaws on the error value, which, in periods of sharp increase in air temperature, may exceed $100 \%$

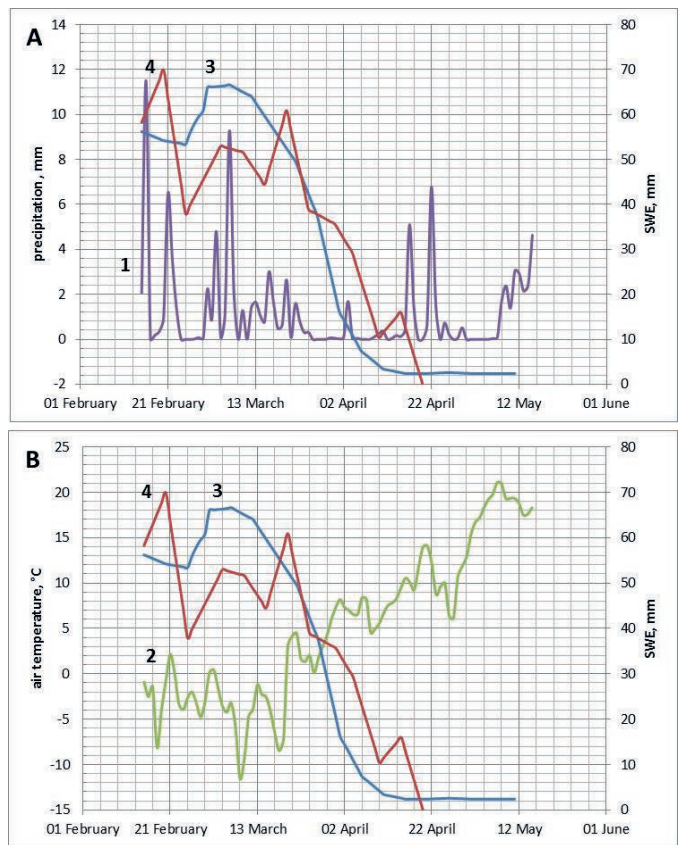

Fig. 2 Comparison of seasonal distributions of SWE and meteorological data for the Don River basin in spring 2010: (A) precipitation, mm, with estimated (2) and in situ (4) SWE; (B) air temperature, ${ }^{\circ} \mathrm{C}$...

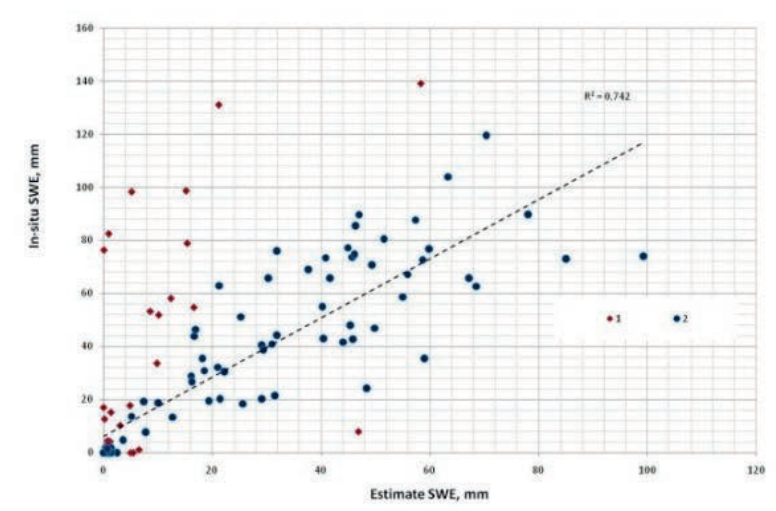

Fig. 3 Linear relationship between in situ and estimated SWE data for the Oka river basin (1) before and (2) after overshoots in SWE values are discarded.

With SWE overshoots, caused by the presence of liquid water in the snowpack during thaws, excluded from the data series, there is a clear linear relationship between the in situ and estimated SWE data (Fig. 3). 
The values for individual years (Fig. 4) show no stratification for separate winters; all values form a unidirectional field of points; thus, the linear relationship mentioned above repeats from year to year. The scatter of points for the Don River basin is smaller (Fig. 4(B)). This allows some transition coefficients to be used to improve the accuracy of SWE estimation in a manner individual for each river basin.
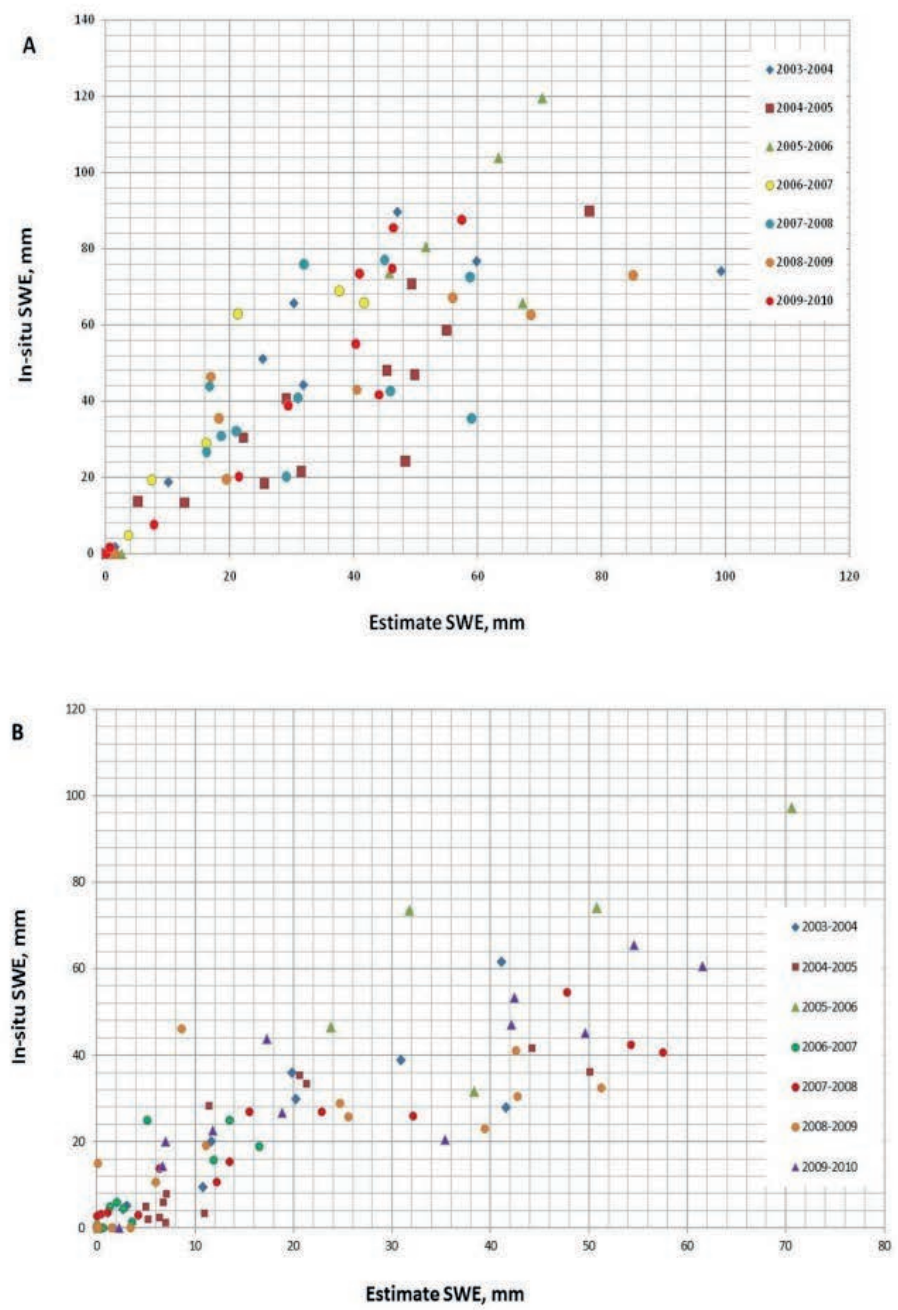

Fig. 4 Linear relationship between the in situ and estimated SWE in different periods for the basins of the Oka (A) and Don (B).

For the Northern Dvina basin, the situation is more complicated. Some general trend can be supposed, but there are considerable changes from year to year and the scatter of the points is very wide. The combined effect of saturation and the presence of liquid water in snowpack in the spring, when snow cover in northern regions is still thick, produces large errors. For some years there is a close relationship between the considered values, which is observed at rather small average SWE values, such as in 2008 and 2010; however, more detailed analysis of the main features of these winters can help to explain the obtained discrepancies.

Moreover, northern river basins generally show a large percentage of forest area. Inaccuracies of retrieval of SWE satellite data due to forest canopy are considered for the northern part of the East European Plain - the basin of the Barents and White seas (above the 60th parallel) (Fig. 5). Thus year-to-year variations of SWE relationships between the remote sensing and in situ data have been investigated for open and forested areas, the smallest discrepancy is observed in open areas (Telegina et al., 2014). 


\section{CONCLUSIONS}

Independent ground-based snow water equivalent observations were used to investigate the estimation uncertainty of remotely sensed passive microwave SWE. The aim of the study is spatial-temporal analysis of the available microwave data of passive remote sensing and the estimation of whether the passive microwave remote sensing can be used for studying snow cover in European Russia. The accuracy of the information obtained by the comparison of these data

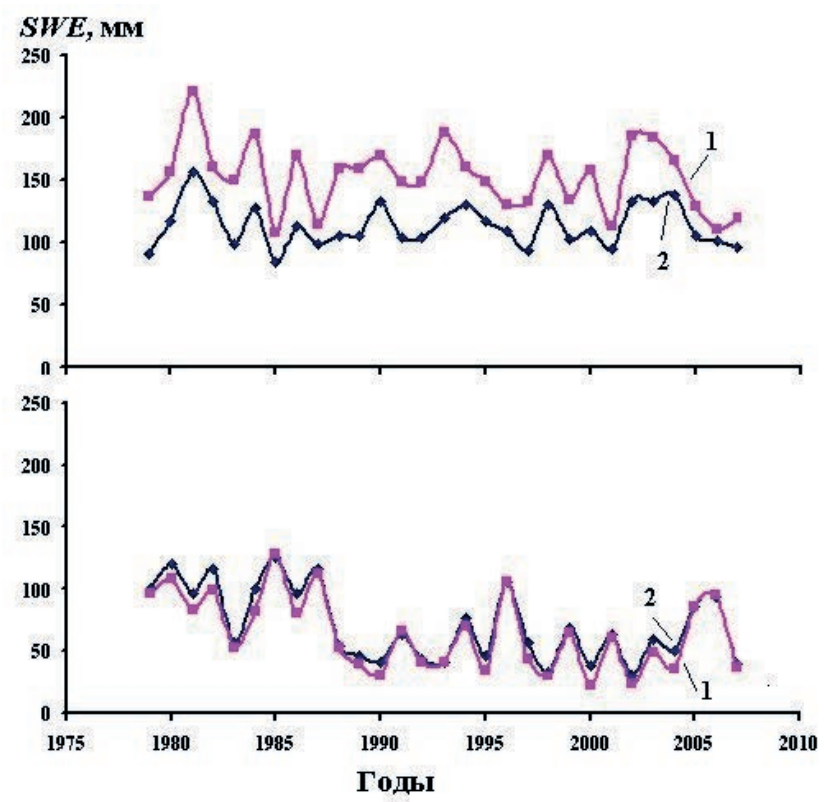

Fig. 5 The basin of the Barents and White seas: differences between the maximal SWE values of forested (1) and open (2) area - in situ (top) and estimated (bottom) data.

with the ground-based SWE data from meteorological stations for long period, the impact of variations of basic meteorological elements on the data accuracy was estimated; also the major factors influencing the uncertainty were revealed and estimated. The errors of the SWE estimate (evaluated as relative root-mean-square deviations) are maximal for the Northern Dvina watershed, the average error being 53\%; for the Oka and Don river basins, the errors are 35 and $33 \%$, respectively. The main problems of remote sensing for northern river basins are due to the thick canopy and high snowpack, whose height exceeds the penetration depth. For the southern regions and midland river basins, a priority problem is the presence of liquid water in the snowpack during thaws and inverse relation between the estimated SWE and the respective air temperature. Furthermore, calculations have shown that the uncertainty also depends on the number of ground-based snow courses. Those factors are taken into account in the initial algorithm of SWE retrieval, but, because of some special features of the studied territory, their re-estimation is required.

Acknowledgements The study was supported by the Russian Foundation for Basic Research, project no. 14-17-00700.

\section{REFERENCE}

Donga, J., Walker, J.P. and Houserd, P.R. (2005) Factors affecting remotely sensed snow water equivalent uncertainty. Remote Sensing of Environment 97, 68-82.

Rango, A. (2000) Spaceborne remote sensing for snow hydrology applications. Hydrological Sciences Journal 41(4).

Tait, A., et al. (2000) Utilizing multiple datasets for snow cover mapping. Rem. Sens. Env.(72), 111-126.

Tedesco. M. and Narvekar. P. (2010) Assessment of the NASA AMSR-E SWE Product, IEEE Journal of Selected Topics in Applied Earth Observations and Remote Sensing 3(1), 141-159.

Telegina, A., et al. (2014) Estimation of precision for snow storage satellite data for large watersheds of European Russia. Current problem in remote sensing of the Earth from space 11(2), 38-49 (in Russian). 